\title{
Article \\ An Origami Paper-Based Analytical Device for Rapid and Sensitive Analysis of Acrylamide in Foods
}

\author{
Yu Yan ${ }^{1,+}$, Dan Zhao ${ }^{1,+}$, Weiming Li $^{1}{ }^{1}$,, Xiaoqian $\mathrm{Li}^{1}$, Yangyang Chang ${ }^{1}$, Qiang Zhang ${ }^{2}$ and Meng Liu ${ }^{1, *}$ \\ 1 Key Laboratory of Industrial Ecology and Environmental Engineering (Ministry of Education), \\ School of Environmental Science and Technology, Dalian University of Technology, Dalian 116024, China; \\ 18234176390@163.com (Y.Y.); xiaoxiaodanluzd@163.com (D.Z.); liwm1990@outlook.com (W.L.); \\ XQLi@mail.dlut.edu.cn (X.L.); yychang@dlut.edu.cn (Y.C.) \\ 2 School of Bioengineering, Dalian University of Technology, Dalian 116024, China; zhangqiang@dlut.edu.cn \\ * Correspondence: mliu@dlut.edu.cn \\ + These authors contributed equally to this work.
}

Citation: Yan, Y.; Zhao, D.; Li, W.; Li, X.; Chang, Y.; Zhang, Q.; Liu, M. An Origami Paper-Based Analytical Device for Rapid and Sensitive Analysis of Acrylamide in Foods. Micromachines 2022, 13, 13. https://doi.org/10.3390/ $\operatorname{mi} 13010013$

Academic Editor: Trieu Nguyen

Received: 16 November 2021

Accepted: 22 December 2021

Published: 23 December 2021

Publisher's Note: MDPI stays neutral with regard to jurisdictional claims in published maps and institutional affiliations.

Copyright: (C) 2021 by the authors. Licensee MDPI, Basel, Switzerland. This article is an open access article distributed under the terms and conditions of the Creative Commons Attribution (CC BY) license (https:// creativecommons.org/licenses/by/ $4.0 /)$.

\begin{abstract}
Rapid and sensitive detection of acrylamide in food samples is important for food safety and public health. Here, we describe a disposable origami paper-based analytical device (denoted doPAD) for colorimetric detection of acrylamide. This device uniquely exploits 3D origami folding paper for spatial control of the target recognition and signal readout, thus resulting in a positive correlation between the signals and the analytes. Under optimal conditions, the device achieved the quantitative analysis of acrylamide with a limit of detection of $1.13 \mu \mathrm{g} / \mathrm{L}$ within $120 \mathrm{~min}$ (including a derivatization time of $90 \mathrm{~min}$ and an assay time of $21 \mathrm{~min}$ ). Furthermore, our method allowed the rapid and sensitive detection of acrylamide in complex food matrices. We envision that the platform described will find useful applications in the fields of food safety and environmental health.
\end{abstract}

Keywords: acrylamide; colorimetric; enzyme linked immunosorbent assay (ELISA); paper-based analytical device

\section{Introduction}

Acrylamide (AA) can be produced by the Maillard reaction of an amino acid, asparagine and reducing sugars (e.g., glucose, fructose) [1,2]. Under different thermal processing conditions, the AA content can vary greatly within the same food [3]. For example, high-carbohydrate foods (e.g., potatoes, cereals) processed at temperature over $120{ }^{\circ} \mathrm{C}$ contain extremely high levels of AA [3]. A large number of animal experiments showed that AA possesses reproductive toxicity, genotoxicity, and severe neurotoxicity [4-6]. This compound has attracted considerable attention in the fields of food safety control due to its negative consequences on health. The International Agency for Research on Cancer (IARC) has classified AA as a suspected chemical carcinogen for humans [7]. In order to limit the content of AA in food, the Commission Regulation (EU) has set the benchmark level of AA in food as 40-4000 $\mathrm{\mu g} \mathrm{kg}^{-1}$ [8]. Hence, there is a significant need for the development of fast, sensitive, inexpensive assays for the detection of AA [9-12].

The commonly used assays for AA include gas chromatography-mass spectrometry (GC-MS) [13-15], and liquid chromatography-mass spectrometry (LC-MS) [16-19]. However, these methods strongly depend on instruments and have inherent disadvantages, including long detection time, complex sample pretreatment, and high cost. Furthermore, the enzyme linked immunosorbent assay (ELISA) has also been reported as a robust and inexpensive method for the detection of AA in foods [20,21]. Currently, there are some commercial ELISA kits for detecting AA based on the direct competitive ELISA. In these tests, enzyme-labeled antigens will compete with free antigens in a sample for binding to a limited amount of capture antibody attached to the surface of the slide, which would produce a target concentration-dependent signal. However, these methods usually need multiple steps and large sample volumes, hence increasing the risk of cross-contamination. 
In addition, there was a negative correlation between the signals and the analytes, thus potentially causing misleading results due to the high background signal [3,22-25]. Our aim of this study is to develop a powerful signal-on immunoassay toward small-molecular AA to change the signal-off situation of the traditional competitive-type immunoassays.

Paper-based analytical devices (PADs) have many advantages, being inexpensive, lightweight, biodegradable, and biocompatible [26,27]. In general, this device is fabricated by cellulose paper, which can drive the liquid without the need of external power supplies because of its natural hydrophilicity and porosity. Various patterning techniques (e.g., deposition, photolithography, and wax printing) could be used to fabricate well-defined channels on paper [28-31]. To date, PADs have evolved from two- to three-dimensional (3D) devices for wide applications in clinical diagnosis, environmental monitoring and food safety [32-38]. In these 3D devices, the origami design was commonly used to provide more user-friendly and multiplex testing. This setup enables the buffer to flow through the devices via capillary action, carrying different bioreagents across the folded layers and thus simplifying multi-step reactions into a single device.

Inspired by these advantages, we developed a disposable origami-based PAD (denoted doPAD) for rapid and accurate analysis of AA in food samples. We employed the concept of 3D origami folding paper to simply separate the antigen-antibody recognition and signal readout, avoiding the potential incompatibilities of reagents located in the same zone. In such way, this system produces a signal-on signal response with the increment of AA concentration in the sample. Furthermore, doPAD offers several advantages in terms of small sample volumes, simplicity and cost-effectiveness. To the best of our knowledge, such a system for quantitative determination of small molecules has not been reported so far.

\section{Materials and Methods}

\subsection{Chemicals and Instruments}

PBS buffer, tetramethylbenzidine (TMB), hydrogen peroxide $\left(\mathrm{H}_{2} \mathrm{O}_{2}\right)$, pullulan, Tween20 and bovine serum albumin (BSA) were obtained from Shanghai Sangon Biological Engineering Technology and Services Co., Ltd. (Shanghai, China). Nitrocellulose paper (HF120 and NC0.45 $\mu \mathrm{M}$ ) were purchased from GE Healthcare (Chicago, IL, USA). The capture antibody of dAA (cAb, with a concentration of $6 \mathrm{mg} / \mathrm{mL}$ ) and horseradish peroxidase-labeled acrylamide derivative (HRP-dAA, with a concentration of $2 \mathrm{mg} / \mathrm{mL}$ ) were supplied by Wuxi Determine Biotechnology Co. Ltd. (Wuxi, China). All other chemicals were obtained from Sigma-Aldrich and used without further purification. Hydrophobic barrier on paper was printed using a Xerox ColorQube $8570 \mathrm{~N}$ solid wax ink printer (Xerox Corporation, Norwalk, CT, USA).

\subsection{Buffers Used in This Work}

$1 \times$ PBS buffer: $8.1 \mathrm{mM} \mathrm{Na}_{2} \mathrm{HPO}_{4}, 1.76 \mathrm{mM} \mathrm{KH}_{2} \mathrm{PO}_{4}, 0.137 \mathrm{mM} \mathrm{NaCl}, 2.683 \mathrm{mM} \mathrm{KCl}$, $\mathrm{pH} 7.4$.

ELISA reaction buffer $(1 \times$ PBST): $1 \times$ PBS, $0.05 \%$ Tween-20, $\mathrm{pH} 7.4$ (note that Tween20 was used as the surfactant to improve the solubility of dAA).

Washing buffer: $1 \times$ PBS, pH 7.4.

Blocking buffer: $1 \times$ PBS containing 2\% BSA, $\mathrm{pH} 7.4$.

Colour buffer: $53.33 \mathrm{mM} \mathrm{HAC}-\mathrm{NaAC}$ buffer containing $2.67 \mathrm{mM} \mathrm{TMB}, 3.33 \mathrm{mM} \mathrm{H}_{2} \mathrm{O}_{2}$, $\mathrm{pH} 4.5$.

\subsection{Fabrication of Disposable Origami Paper-Based Analytical Device (doPAD)}

Large sheets of nitrocellulose filter paper (NC 0.45) and nitrocellulose membrane (HF120) were cut to standard letter sheet size $(8.5 \times 11$ inches $)$ to be fed into the inkjet printer. The proposed doPAD is comprised of two layers. On the first layer, Zone 1 was printed onto a nitrocellulose filter paper using a wax printer (Xerox ColourQube 8570N), followed by heating at $120^{\circ} \mathrm{C}$ for $2 \mathrm{~min}$. The wax was melting into the pore structure of cellulose to form the hydrophobic barriers. On the second layer, Zone 2 was printed onto a 
nitrocellulose membrane using the above wax-printing method. This produced a paper device with a circular zone of diameter $4.5 \mathrm{~mm}$ (Zone 1), and a second circular zone of diameter $7 \mathrm{~mm}$ (Zone 2). These two layers were assembled together using an adhesive tape. We added $6 \mu \mathrm{L}$ of $\mathrm{cAb}$ (dilution ratio: 1/100; final concentration: $0.06 \mathrm{mg} / \mathrm{mL}$ ) to Zone 1, followed by incubation at room temperature (RT) for $10 \mathrm{~min}$ before washing twice with $100 \mu \mathrm{L}$ of washing buffer. We then added $25 \mu \mathrm{L}$ of blocking buffer and incubated it at RT for $25 \mathrm{~min}$. After washing twice in $100 \mu \mathrm{L}$ of washing buffer, the bioactive paper was dried at RT. We then inkjet-printed $6 \mu \mathrm{L}$ of $10 \%$ pullulan $(w / v)$ solution on to Zone 1 . The doPAD was dried and stored at RT in a desiccant container.

\subsection{Synthesis of Acrylamide Derivative}

We mixed $50 \mathrm{mg}$ of AA, $95 \mathrm{mg}$ of p-mercaptobenzoic acid (4-MPA), $40 \mathrm{mg}$ of $\mathrm{NaHCO}_{3}$ and $5 \mathrm{~mL}$ of double-distilled water $\left(\mathrm{ddH}_{2} \mathrm{O}\right)$ and stirred this in darkness at $37^{\circ} \mathrm{C}$ for $90 \mathrm{~min}$. The reaction mixture was then acidified to $\mathrm{pH} 2.0$ with $1 \mathrm{M} \mathrm{HCl}$. After vacuum filtration, the precipitate was washed three times with $\mathrm{ddH}_{2} \mathrm{O}$. Acrylamide derivatives (dAA) were then obtained after drying, and dissolved in $200 \mu \mathrm{L}$ of methanol.

\subsection{Acrylamide Derivatives (dAA) Detection}

We mixed $1 \mu \mathrm{L}$ of dAA (final concentration: 10-5000 $\mu \mathrm{g} / \mathrm{L}$ ) and $5 \mu \mathrm{L}$ of HRP-dAA (dilution ratio: 1/2000) and added this to Zone 1. Following incubation at RT for $10 \mathrm{~min}$, Zone 1 was folded on to Zone 2 before adding $20 \mu \mathrm{L}$ of washing buffer, thus resulting in vertical diffusion of reaction mixtures to Zone 2 . This was allowed to proceed for $10 \mathrm{~min}$ before adding $15 \mu \mathrm{L}$ of colour buffer to initiate the colorimetric reaction. JPEG images were taken within 1 min by a Huawei P30 in a homemade mobile phone holder at a set distance from the paper (about $10 \mathrm{~cm}$ high) in the dark. ImageJ software was used to analyze the JPEG images using an 8-bit color scale. The images were then inverted, so that Zone 2, that was originally white, became black. Based on this scale, an increase in the color resulted in an increase in color intensity of the Zone 2.

\subsection{Specificity}

Methylacrylamide, gluotamate, maltose and kanamycin were used as non-target controls. These molecules were first derivatized by 4-MPA according to the procedure for the synthesis of acrylamide derivative, and then subjected to analysis using the identical procedure as described above.

\subsection{Real Sample Test}

Food samples (biscuits, fries) purchased from local supermarkets were dried and homogenized by grinding. $1 \mathrm{~g}$ of the obtained samples and $10 \mathrm{~mL}$ of $0.1 \%$ formic acid $/ \mathrm{ddH}_{2} \mathrm{O}$ were added into a $50 \mathrm{~mL}$ centrifuge tubes. The tube was then vigorously vortexed for $10 \mathrm{~min}$ and centrifuged at $8200 \times \mathrm{g}$ for $10 \mathrm{~min}$ at $4{ }^{\circ} \mathrm{C}$ [21]. The supernatant was defatted twice with $10 \mathrm{~mL}$ of $\mathrm{n}$-hexane [24], followed by passing through $0.22 \mu \mathrm{M}$ filter membrane. The above solutions were spiked with different concentrations of AA. After being derivatized by 4-MPA, the samples containing dAA were analyzed using doPAD.

\section{Results and Discussion}

\subsection{Working Principle of doPAD}

AA derivative, named dAA (Figure 1a and Figure S1), was first synthesized and used as the target for recognizing the coated capture antibody $(\mathrm{cAb})$ on paper. The paper device, illustrated in Figure 1b, consists of two pieces of paper chips folding onto each other. The first piece is configured to be a molecular recognition zone (Zone 1 ), and the second piece contains a colorimetric readout zone (Zone 2). Zone 1 and Zone 2 are demarcated onto nitrocellulose papers using wax barriers. 


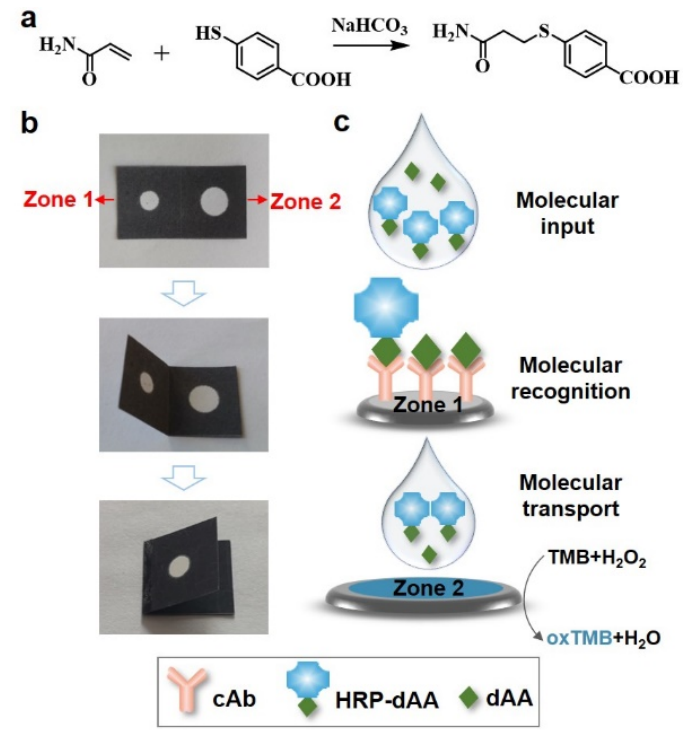

Figure 1. (a) Synthesis of acrylamide (AA) derivative, named dAA. (b) A foldable disposable origami paper-based analytical device (doPAD), and (c) its working principle.

To produce a sensor (Figure 1c), Zone 1 was first inkjet-printed with the $\mathrm{cAb}$, blocked by BSA, and then inkjet-printed with a $10 \%$ pullulan $(w / v)$ solution. A transparent pullulan film was obtained after drying at RT. In a typical test, HRP-dAA and dAA in $1 \times$ PBST buffer were simultaneously added to Zone 1 . The pullulan films will be dissolved, thus allowing the competitive binding between $\mathrm{cAb} / \mathrm{HRP}-\mathrm{dAA}$ and $\mathrm{cAb} / \mathrm{dAA}$. By folding Zone 1 onto Zone 2, any unbound HRP-dAA and dAA are transferred to Zone 2 driven by capillary action. These unbounded HRP-dAA molecules will further oxidize $3,3^{\prime}, 5,5^{\prime}$ tetramethylbenzidine (TMB) in the presence of $\mathrm{H}_{2} \mathrm{O}_{2}$, thus generating a colorimetric readout at Zone 2. In the absence of $\mathrm{dAA}$, no colorimetric signal was produced at Zone 2 because HRP-dAA was expected to bind the coated $\mathrm{cAb}$ at Zone 1 . Therefore, the color intensity (Zone 2) generated was proportional to the concentrations of dAA. The device could quantify dAA within $21 \mathrm{~min}$, including a target recognition time of $10 \mathrm{~min}$, a vertical diffusion time of $10 \mathrm{~min}$ and a colorimetric reaction time of $1 \mathrm{~min}$.

\subsection{Feasibility of doPAD}

We first investigated the feasibility of performing the colorimetric detection of dAA on paper. In the absence of $\mathrm{cAb}$, a colorimetric signal was produced at the Zone 2 when HRP-dAA was provided both without (Figure 2, lane 3) and with dAA (lane 4), suggesting that HRP-dAA molecules can be easily transported to the Zone 2 . In the presence of $c A b$, we only observed a strong colorimetric signal with the addition of dAA (lane 8). This data indicated that the competitive binding between $\mathrm{cAb} / \mathrm{HRP}-\mathrm{dAA}$ and $\mathrm{cAb} / \mathrm{dAA}$ at Zone 1 , thus resulting in the vertical transport of unbound HRP-dAA to Zone 2. In addition, no significant signal was produced when dAA was omitted (lane 7), suggesting that most HRP-dAA molecules bind the coated cAb at Zone 1. 


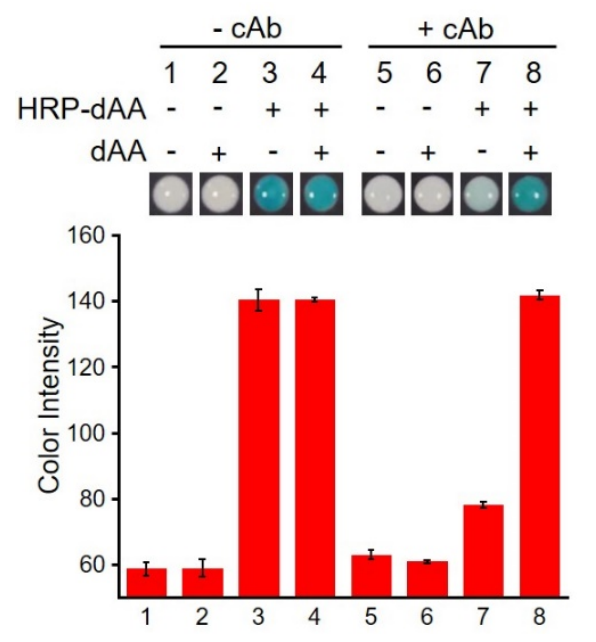

Figure 2. Analysis of dAA by doPAD.

\subsection{Optimization of doPAD}

Many parameters may affect the performance of doPAD. We first optimized the maximum binding capacity of $\mathrm{cAb}$ onto Zone 1 (Figure $3 \mathrm{a}$ ). cAb with certain dilution ratios was first added onto Zone 1 and dried at RT. After blocking with BSA, Zone 1 was washed twice to remove the unbound molecules. With the addition of HRP-dAA, the colorimetric signal produced at Zone 1, defined as the signal-to-background ratio (S/B), gradually increased with decreasing the dilution ratios of $\mathrm{cAb}$ from $1 / 5000$ to $1 / 10$. A dilution ratio of $1 / 100$ was used in the following study. We next examined the amounts of HRP-dAA to achieve a low background signal at Zone 2. The key requirement was that HRP-dAA should bind the coated $\mathrm{cAb}$ at Zone 1 without the presence of dAA. As shown in Figure $3 b$, the background signal was decreased at Zone 2 by increasing the dilution ratios of HRP-dAA from 1/100 to $1 / 2000$ at Zone 1 . Thus, a dilution ratio of 1/2000 was used to ensure a low background signal. Finally, we performed a kinetic experiment to assess the time required to reach the binding equilibrium between immobilized $c A b$ and HRP-dAA (or dAA). HRP-dAA and dAA were incubated at Zone 1 for different time periods prior to paper folding and analysis. The maximum colorimetric signal was observed when the incubation time was $10 \mathrm{~min}$.
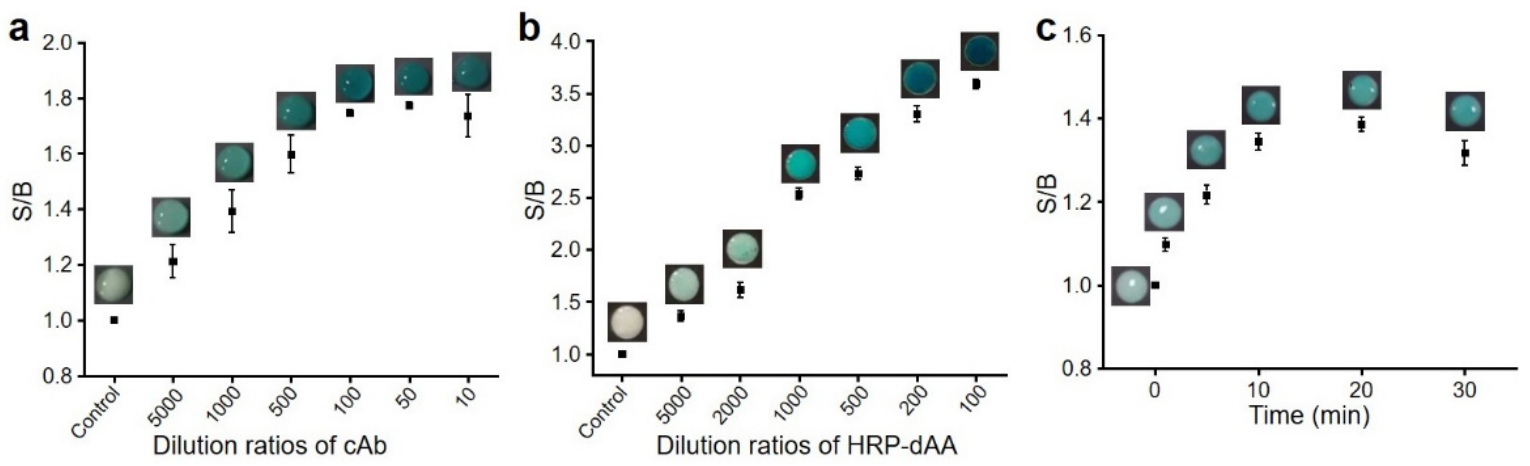

Figure 3. Effects of (a) dilution ratios of $\mathrm{cAb}$, (b) dilution ratios of horseradish peroxidase-labeled acrylamide derivative (HRP-dAA) and (c) incubation time on signal-to-background ratios (S/B).

\subsection{Performance of doPAD}

We utilized this proposed doPAD for the detection of AA. Figure 4a shows the images of colorimetric responses of Zone 2 as a function of AA concentration. The response curve was obtained by measuring the color intensity using ImageJ for each paper well array. It was observed that the S/B values gradually increased with increasing AA concentrations. 
A detection limit of $1.13 \mu \mathrm{g} / \mathrm{L}$ was obtained on the basis of the $3 \mathrm{~s} /$ slope $(\mathrm{s}$, standard deviation of the blank samples).

a

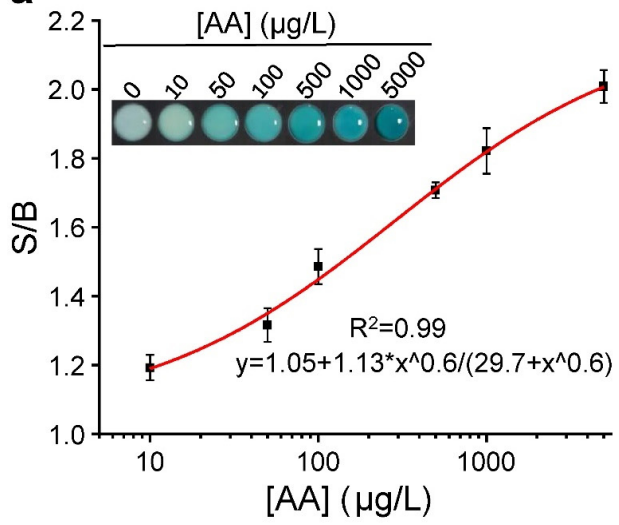

b

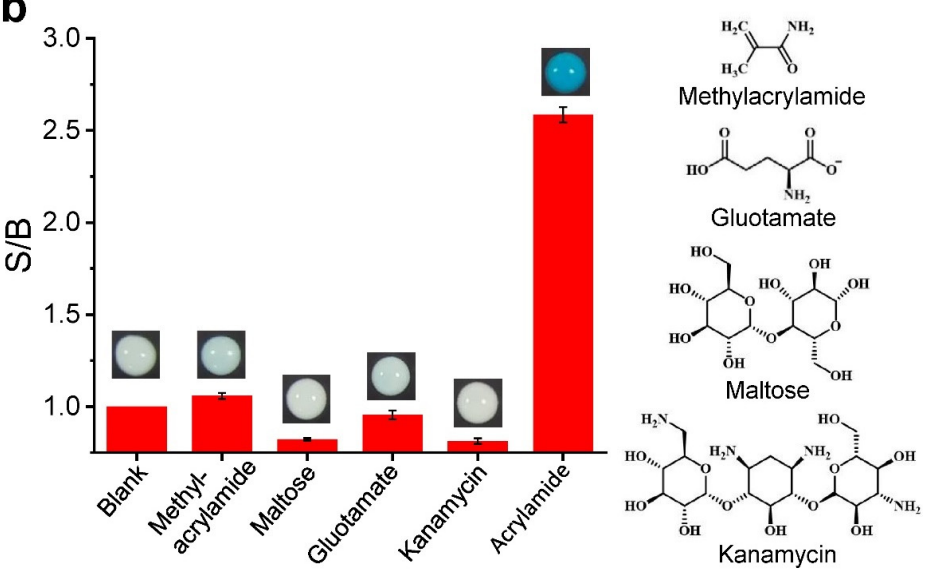

Figure 4. (a) Sensitivity and (b) specificity of the proposed doPAD.

Besides the high sensitivity, each doPAD also exhibited excellent selectivity for its cognate target (Figure $4 \mathrm{~b}$ ). No obvious colorimetric signal was observed when each system was tested with other unintended small compounds: methylacrylamide, gluotamate, maltose and kanamycin.

We next evaluate the stability and the reproducibility of the doPADs. A group of devices were stored at RT in the dark and tested over a period of 15 days. The devices remained at approximately $80 \%$ of their initial activity (Figure S2). When comparing between 30 individual paper sensors, a coefficient of variation of $8.2 \%$ was obtained, indicating the good reproducibility of this device (Figure S3).

We also challenged the doPAD by analyzing AA spiked in complex food matrices represented by biscuits and fries (Figure 5). This experiment shows that background materials in these complex samples do not significantly affect the outcome of the results. A strong colorimetric signal was observed upon addition of the target, producing S/B values that were proportional to the spiked AA concentration. One observed that the developed doPAD displayed recoveries ranging from $82 \%$ to $106 \%$ for the food samples along with a relative standard deviation (RSD) below $8 \%$ (Table 1 ). This result suggested the potential applicability of our assay for the quantification of AA in real food samples.

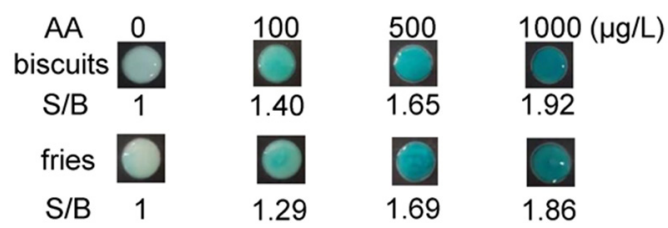

Figure 5. Detection of AA in the presence of complex sample matrices represented by biscuits and fries.

Table 1. Recovery (\%) and relative standard deviation (RSD, \%) of the proposed doPAD in the detection of AA with different concentrations.

\begin{tabular}{cccc}
\hline Samples & Added $(\mu \mathrm{g} / \mathrm{L})$ & Recovery $(\%)$ & RSD (\%) \\
\hline \multirow{3}{*}{ biscuits } & 100 & $82-95$ & 7.14 \\
& 500 & $95-106$ & 5.42 \\
\multirow{2}{*}{ fires } & 1000 & $96-105$ & 5.22 \\
& 100 & $85-94$ & 5.31 \\
& 500 & $96-106$ & 7.27 \\
& 1000 & $95-104$ & 6.16 \\
\hline
\end{tabular}




\section{Conclusions}

In summary, we have demonstrated a cost-effective, integrated paper-based analytical device for colorimetric detection of AA in food products. The device features three components: a capture antibody for its ability to selectively recognize the small molecule on paper, origami paper for the precise control of the fluidic flow, and HRP for its ability to amplify each recognition event into colorimetric signals that can be easily detected. The detection limit of $1.13 \mu \mathrm{g} / \mathrm{L}$ was achieved within $120 \mathrm{~min}$. The advantage of the sensitive and rapid analysis may help for in-time detection of toxic chemicals in the field of food safety. Although we have provided illustrative examples for detecting acrylamide in food samples, this approach could be easily extended to other types of small molecules. Future work will include integration of the sample extraction module with this paper-based device to increase its portability and usability in remote settings.

Supplementary Materials: The following supporting information can be downloaded at https: / / www.mdpi.com/article/10.3390/mi13010013/s1, Figure S1: HR-MS of dAA; Figure S2: stability; Figure S3: reproducibility.

Author Contributions: M.L. and Y.C. designed the project; Y.Y., D.Z. and X.L. performed the experiments and discussed the experimental results; M.L., Q.Z. and W.L. analyzed the data and wrote the paper. All authors have read and agreed to the published version of the manuscript.

Funding: Funding for this work was provided by the National Key R\&D Program of China (2018YFC1602306, 2019YFC1905401), and National Natural Science Foundation of China (NSFC; Grant No. 21922601).

Conflicts of Interest: The authors declare no competing financial interest.

\section{References}

1. Mottram, D.S.; Wedzicha, B.L.; Dodson, A.T. Acrylamide is formed in the Maillard reaction. Nature 2002, 419, 448-449. [CrossRef]

2. Stadler, R.H.; Blank, I.; Varga, N.; Robert, F.; Hau, J.; Guy, P.A.; Robert, M.C.; Riediker, S. Acrylamide from Maillard reaction products. Nature 2002, 419, 449-450. [CrossRef]

3. Franek, M.; Rubio, D.; Diblikova, I.; Rubio, F. Analytical evaluation of a high-throughput enzyme-linked immunosorbent assay for acrylamide determination in fried foods. Talanta 2014, 123, 146-150. [CrossRef]

4. Larguinho, M.; Cordeiro, A.; Diniz, M.S.; Costa, P.M.; Baptista, P.V. Metabolic and histopathological alterations in the marine bivalve mytilus galloprovincialis induced by chronic exposure to acrylamide. Environ. Res. 2014, 135, 55-62. [CrossRef]

5. Karimani, A.; Hosseinzadeh, H.; Mehri, S.; Jafarian, A.H.; Kamali, S.A.; Mohammadpour, A.H.; Karimi, G. Histopathological and biochemical alterations in non-diabetic and diabetic rats following acrylamide treatment. Toxin Rev. 2021, 40, 277-284. [CrossRef]

6. Zhang, Y.; Ren, Y.P.; Zhang, Y. New research developments on acrylamide: Analytical chemistry, formation mechanism, and mitigation recipes. Chem. Rev. 2009, 109, 4375-4397. [CrossRef]

7. $\mathrm{Hu}, \mathrm{Q} . ; \mathrm{Xu}, \mathrm{X} . ; \mathrm{Fu}, \mathrm{Y} . ; \mathrm{Li}, \mathrm{Y}$. Rapid methods for detecting acrylamide in thermally processed foods: A review. Food Control 2015, 56, 135-146. [CrossRef]

8. Zhuang, Y.T.; Ma, L.; Huang, H.; Han, L.; Wang, L.; Zhang, Y. A portable kit based on thiol-ene Michael addition for acrylamide detection in thermally processed foods. Food Chem. 2022, 373, 131465. [CrossRef] [PubMed]

9. Yager, P.; Domingo, G.J.; Gerdes, J. Point-of-care diagnostics for global health. Annu. Rev. Biomed. Eng. 2008, 10, 107-144. [CrossRef] [PubMed]

10. Giljohann, D.A.; Mirkin, C.A. Drivers of biodiagnostic development. Nature 2009, 462, 461-464. [CrossRef] [PubMed]

11. Gubala, V.; Harris, L.F.; Ricco, A.J.; Tan, M.X.; Williams, D.E. Point of care diagnostics: Status and future. Anal. Chem. 2012, 84, 487-515. [CrossRef]

12. Nayak, S.; Blumenfeld, N.R.; Laksanasopin, T.; Sia, S.K. Point-of-care diagnostics: Recent developments in a connected age. Anal. Chem. 2017, 89, 102-123. [CrossRef]

13. Omar, M.M.A.; Ibrahim, W.A.W.; Elbashir, A.A. Sol-gel hybrid methyltrimethoxysilane-tetraethoxysilane as a new dispersive solid-phase extraction material for acrylamide determination in food with direct gas chromatography-mass spectrometry analysis. Food Chem. 2014, 158, 302-309. [CrossRef]

14. Lee, M.R.; Chang, L.Y.; Dou, J. Determination of acrylamide in food by solid-phase microextraction coupled to gas chromatography-positive chemical ionization tandem mass spectrometry. Anal. Chim. Acta 2007, 582, 19-23. [CrossRef]

15. Mastovska, K.; Lehotay, S.J. Rapid sample preparation method for LC-MS/MS or GC-MS analysis of acrylamide in various food matrices. J. Agric. Food Chem. 2006, 54, 7001-7008. [CrossRef] 
16. Kim, T.H.; Shin, S.; Kim, K.B.; Seo, W.S.; Shin, J.C.; Choi, J.H.; Weon, K.Y.; Joo, S.H.; Jeong, S.W.; Shin, B.S. Determination of acrylamide and glycidamide in various biological matrices by liquid chromatography-tandem mass spectrometry and its application to a pharmacokinetic study. Talanta 2015, 131, 46-54. [CrossRef]

17. Bortolomeazzi, R.; Munari, M.; Anese, M.; Verardo, G. Rapid mixed mode solid phase extraction method for the determination of acrylamide in roasted coffee by HPLC-MS/MS. Food Chem. 2012, 135, 2687-2693. [CrossRef]

18. Lim, H.H.; Shin, H.S. A new derivatization approach with D-cysteine for the sensitive and simple analysis of acrylamide in foods by liquid chromatography-tandem mass spectrometry. J. Chromatogr. A 2014, 1361, 117-124. [CrossRef]

19. Senyuva, H.Z.; Gökmen, V. Interference-free determination of acrylamide in potato and cereal-based foods by a laboratory validated liquid chromatography-mass spectrometry method. Food Chem. 2006, 97, 539-545. [CrossRef]

20. Sun, Q.; Xu, L.; Ma, Y.; Qiao, X.; Xu, Z. Study on a biomimetic enzyme-linked immunosorbent assay method for rapid determination of trace acrylamide in French fries and cracker samples. J. Sci. Food Agric. 2014, 94, 102-108. [CrossRef]

21. Andrew, P.; Terence, F.; Christopher, E. Development of a high-throughput enzyme-linked immunosorbent assay for the routine detection of the carcinogen acrylamide in food, via rapid derivatisation pre-analysis. Anal. Chim. Acta 2008, 608, 178-185.

22. Quan, Y.; Chen, M.; Zhan, Y.; Zhang, G. Development of an enhanced chemiluminescence ELISA for the rapid detection of acrylamide in food products. J. Agric. Food Chem. 2011, 59, 6895-6899. [CrossRef]

23. Singh, G.; Brady, B.; Koerner, T.; Becalski, A.; Zhao, T.; Feng, S.; Godefroy, S.B.; Huet, A.C.; Delahaut, P. Development of a highly sensitive competitive indirect enzyme-linked immunosorbent assay for detection of acrylamide in foods and water. Food Anal. Methods 2014, 7, 1298-1304. [CrossRef]

24. Wu, J.; Shen, Y.D.; Lei, H.T.; Sun, Y.M.; Yang, J.Y.; Xiao, Z.L.; Wang, H.; Xu, Z.L. Hapten synthesis and development of a competitive indirect enzyme-linked immunosorbent assay for acrylamide in food samples. J. Agric. Food Chem. 2014, 62, 7078-7084. [CrossRef]

25. Zhu, Y.T.; Song, S.S.; Liu, L.Q.; Kuang, H.; Xu, C.L. An indirect competitive enzyme-linked immunosorbent assay for acrylamide detection based on a monoclonal antibody. Food Agric. Immunol. 2016, 27, 796-805. [CrossRef]

26. Hu, J.; Wang, S.; Wang, L.; Li, F.; Pingguan-Murphy, B.; Lu, T.J.; Xu, F. Advances in paper-based point-of-care diagnostics Biosens. Bioelectron. 2014, 54, 585-597. [CrossRef]

27. Martinez, A.W.; Phillips, S.T.; Whitesides, G.M.; Carrilho, E. Diagnostics for the developing world: Microfluidic paper-based analytical devices. Anal. Chem. 2010, 82, 3-10. [CrossRef]

28. Lam, T.; Devadhasan, J.P.; Howse, R.; Kim, J. A chemically patterned microfluidic paper-based analytical device (C- $\mu$ PAD) for point-of-care diagnostics. Sci. Rep. 2017, 7, 1188. [CrossRef]

29. Asano, H.; Shiraishi, Y. Development of paper-based microfluidic analytical device for iron assay using photomask printed with 3D printer for fabrication of hydrophilic and hydrophobic zones on paper by photolithography. Anal. Chim. Acta 2015, 883, 55-60. [CrossRef]

30. Sun, Y.; Chang, Y.; Zhang, Q.; Liu, M. An origami paper-based device printed with DNAzyme-containing DNA superstructures for Escherichia coli detection. Micromachines 2019, 10, 531. [CrossRef]

31. Tenda, K.; Ota, R.; Yamada, K.; Henares, T.G.; Suzuki, K.; Citterio, D. High-resolution microfluidic paper-based analytical devices for sub-microliter sample analysis. Micromachines 2016, 7, 80. [CrossRef]

32. Al-Tamimi, M.; Shen, W.; Zeineddine, R.; Tran, H.; Garnier, G. Validation of paper-based assay for rapid blood typing. Anal. Chem. 2012, 84, 1661-1668. [CrossRef] [PubMed]

33. Liu, H.; Xiang, Y.; Lu, Y.; Crooks, R.M. Aptamer-based origami paper analytical device for electrochemical detection of adenosine. Angew. Chem. 2012, 51, 6925-6928. [CrossRef]

34. Cheng, C.; Martinez, A.W.; Gong, J.; Mace, C.R.; Phillips, S.T.; Carrilho, E.; Mirica, K.A.; Whitesides, G.M. Paper-based ELISA Angew. Chem. 2010, 49, 4771-4774. [CrossRef] [PubMed]

35. Martinez, A.W.; Phillips, S.T.; Butte, M.J.; Whitesides, G.M. Patterned paper as a platform for inexpensive, low-volume, portable bioassays. Angew. Chem. 2007, 46, 1318-1320. [CrossRef]

36. Li, M.; Tian, J.; Al-Tamimi, M.; Shen, W. Paper-based blood typing device that reports patient's blood type "in writing". Angew. Chem. 2012, 51, 5497-5501. [CrossRef] [PubMed]

37. Mao, X.; Huang, T.J. Microfluidic diagnostics for the developing world. Lab Chip 2012, 12, 1412-1416. [CrossRef]

38. Liu, M.; Zhang, Q.; Kannan, B.; Botton, G.A.; Yang, J.; Soleymani, L.; Brennan, J.D.; Li, Y. Self-assembled functional DNA superstructures as high-density and versatile recognition elements for printed paper sensors. Angew. Chem. 2018, 57, 12440-12443. [CrossRef] 